Marina Pantoja Boechat, Débora de Carvalho Pereira:

\title{
Reverse mediations: digital methods of social research for digital citizen- ship
}

\begin{abstract}
:
Our society is heavily mediated by information technologies, so the simplest interactions become traceable, which collaborates to a deluge of data. They represent an abundant source for social analysis and an unparalleled opportunity for citizens to access, produce and disseminate information. Nevertheless, all this affluence of data, for presenting itself in a scattered way, also poses significant difficulties for achieving an integrated view of social reality and its interactions, and is organized in many competing interfaces and information architectures, that may produce, reinforce and disseminate ideologies, hegemonic discourse and platform biases. We identify an emerging field of dispute of the place of mediation of the many flows of information, and efforts for repurposing and restructuring these flows over the seamless structuring of different competing architectures. In order to describe some of these efforts, we draw examples from the field of controversy mapping, and propose the concept of reverse mediation.
\end{abstract}

\section{Agenda:}

Introduction .................................................................................................................. 72

Architectures of information and their encodings ............................................................... 73

Digital social research and online media ......................................................................... 74

Repurposing the platform, revealing the debate................................................................ 75

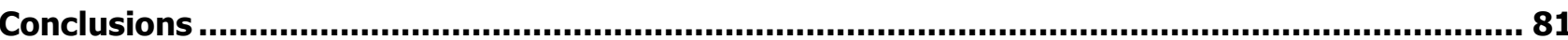

\section{Authors:}

Dr. Marina Pantoja Boechat:

- $\quad$ PhD in Communications and Culture, Escola de Comunicação da Universidade Federal do Rio de Janeiro (Eco-UFRJ), Brazil.

- $\triangle$ marina.boechat@gmail.com

Dr. Débora de Carvalho Pereira

- $\quad$ médialab Sciences Po Paris

- $₫$ debcarpe@gmail.com 


\section{Introduction}

The emergence of the internet is celebrated not just for broadening access to information, but also for redistributing the tools for producing, publishing and sharing information, therefore providing a wider range of resources for citizen participation and public debate in general. For the most part of the last thirty years since the internet has been made broadly available, this signalled to the creation of new independent media outlets that would question hegemonic flows of information and develop critical standpoints to the biases in mass publications. Achieving better representations of social events would involve giving room to independent voices and a wider variety of sources of information. Traditional media companies, in turn, no longer had the exclusivity of publication means, so were forced to reposition their activities and procedures, mostly developing strategies for reader participation and for improving the penetration of their content in social media and other collaborative platforms (see, for example, The New York Times, 2014). Both these developments - the multiplication of information sources and repositioning of media companies' strategies - are set against a complex background of dispute regarding the interpretation and contextualization of social events and interactions, regarding the way in which society is technically mediated.

This radical reorganization of the media landscape will, of course, lead to a dramatic increase in the production of online data, either by content produced by specialists or common citizens, either by data and metadata about our activities as we interact with information systems. With more channels and tools there is also a disaggregation of the media landscape in ever more fractured narratives and competing information architectures, which amounts to an emerging field of dispute, not exactly of the origin or property of information, but of the place of mediation and organization of the many flows of information. This dispute is present in part of the work of traditional media and their strategies for information production and dissemination, but is also present inside new models like social media - think of the algorithms that organize feeds in Facebook, for example.

For the purpose of our work, we are pointing to the fact that these features and structures - like hashtags, character limit in Twitter messages, the fields we should fill to build our online profile and so on - seamlessly organize and structure debate and messages in the making, but are seldom perceived by users as such. We understand that this has profound political effects, such as creating incompatible discursive spaces, with incompatible discursive resources, and framing the ways in which socially shared meaning is produced. We believe that research methods that repurpose circulating information and question and reveal platform biases in order to get to more integrated descriptions of social events can have a deep effect in citizenship and public engagement.

Therefore, besides the very relevant challenges related to adequately storing and recovering all this deluge of data and the necessary discussion about privacy and surveillance in today's digitally mediated societies, we will draw attention to the ways in which this affluence of data may be harnessed, at the same time, as an abundant source for social analysis, and as an unparalleled opportunity for recomposing spaces for debate and citizen participation. Our general goal is to explore this field of dispute about the place of mediation of information flows by proposing the concept of reverse mediation: a set of procedures we see emerging in methods of digital social research and in some of their appropriations for digital citizenship. As we are going to see in detail in the next section, these methods involve extracting data from varied online sources, taking advantage and transforming the architectures in which they are published, and afterwards building visualizations that serve as analysis and communication tools. We understand that this reprocessing and repurposing of information reverses mediations, not in the sense of inverting flows, but in the sense of problematizing and surpassing information structures.

We will be discussing controversy mapping, a method of digital social research that is largely based in ANT (actor-network theory) and was developed initially at SciencesPo Paris, from the work of Bruno Latour. It aims at building visual tools based on data that would display controversies and their complexity. Controversies are regarded as situations where the complexity of social issues becomes evident, where stabilized assumptions and social assemblages are questioned and can therefore be better described. Latest developments of the method have been pointing to integrating the actors of the controversies into the map-making process, easing 
the adoption and the improvement of maps of controversy outside the walls of the academia, as tools for citizen participation in collective concerns. As other research centers start working with controversy mapping and similar methods, we see variations that are more directly aimed at equipping social movements and protesters, mixing social research with direct efforts towards social change.

So we have three main issues: the fragmentation of the media landscape and the role of information architectures in shaping public debate; the role and challenges of digital methods of social research, especially controversy mapping; and the possibilities offered by procedures that reverse mediations. In the pages that follow, first we detail the first two issues and how they appear in the literature of digital methods of social research and controversy mapping, while also using references of information sciences and media studies. Second, we discuss examples of maps of controversy that were produced in Emaps, a European research project dedicated to mobilizing online data to produce maps to foster public debate. This will give us the opportunity to clarify and discuss the challenges and importance of reversing mediations. We conclude by pointing to the political importance of reversing mediations.

\section{Architectures of information and their encodings}

While medias and information systems constantly propose structures and specific contextualizations to describe events and organize data flows, researchers like the ones who work with controversy mapping extract data from circulating information and build tools for analysis and new syntheses about social life. These processes repurpose and restructure the available flows and interfaces of communication, and have at their core the deep concern for the effects of platforms in framing discourse. This leads us to advance the concept of reverse mediation, where social complexity is not only filtered or structured for exploration, but also reprocessed.

First we should refer to Stuart Hall (1993) in order to describe the role of these different information architectures in structuring discourse, circulation and interpretation, and attributing meaning in heavily mediated societies. While discussing mass media messages, the author describes the articulation of four moments: production, circulation, distribution/consumption and reproduction of messages. They represent a set of interconnected practices that influence the other moments without fully defining them. They form social practices and inform further reproduction of messages:

"Once accomplished, the discourse must then be translated - transformed again - into social practices if the circuit is to be both completed and effective. If no 'meaning' is taken, there can be no 'consumption'. If the meaning is not articulated in practice, it has no effect." (p.91).

So messages are encoded in their production and decoded in their consumption, but, for Hall, the codes used at each moment will not be equal: there are many differences of position, once the relation between the public and the medias is not horizontal and the situation of those moments differs greatly. Hall also posits that the possibility of a closer alignment between the codes used in encoding and decoding moments does not point to a more natural, transparent or realistic representation, but to the presence of deeply rooted habits in which this dominant code is set.

However changing and polysemic the many socially shared codes may be, any culture tends to impose its classifications of the social, cultural and political world in a dominant cultural order that organizes different discursive spaces of dominant meanings, that will reflect the continuation, reinforcement or challenging of power and ideology. Every new event, however disruptive of this order it may be, will have to be assigned to a certain discursive domain in order to make sense in general terms. According to Hall, this assignment mobilizes a set of performative rules, that develop competences and uses, in order to reinforce one semantic domain over the other at each situation, and move items from one setting to another, transforming their affiliation and meaning.

Of course, in a communicational environment dominated by mass media, the major flows are more visible, but, at the reception and consumption moments, the processes of decoding are not really visible in their complexity, 
hidden as they are under the dominant flows and encodings. Therefore, dominant codes are more easily regarded as transparent, their strategies hidden in plain sight. Online media, on the other hand, connects the decoding practices to publishing and social indexing (Guedes, Moura, \& Dias, 2011) tools, and collaborates for multiplying discursive spaces and the criteria by which they might be organized. This highlights the importance of communication infrastructures and interfaces for the constitution of cohese discursive spaces that become frames for what can be said and how it should be said. They participate in structuring discourse and information through many different matrixes, in general relying on different codes, inside varied maps of meaning.

A few of the tools that are proposed in online platforms are not exactly aimed at publishing, but connected to organizing the ways in which the content will be stored and will circulate. To an extent, the user activity channeled through these tools will create information flows and networks of related content. For example: tools of social tagging allow users to collaborate for the representation of web content by assigning personalized tags to items in collaborative platforms. On the other end, the tags created by individual users are available for the use of the whole community and they also organize and provide access to the items tagged. A collaborative indexing system always has to be matched to a representational system that interprets and fits the set of tagged items into an interface. This is a kind of bottom-up indexing system that allows for informal and natural language use inside information systems (Noruzi, 2006). Nevertheless, it also gives detailed and relational information about patterns of use and user preferences, feeding strategies of content structuring and distribution according to interpretations and translations of online activity that are once more out of the reach of the users. It also creates a landscape of connected content that is usually not visible in its complexity: the representations in the interfaces do not give access to the exploration of possible patterns that would help building critical standpoints about the indexes.

The strategy of using the traces left by users inside online platforms has been used by many fields, in order to organize representations of content, sell products, target services and advertisement and so on. It is part of this dispute we have been referring to, about the place and shape of the mediation of information flows. Nevertheless, harnessing these objects for scientific research involves different concerns than the ones present in commercial use, and these concerns, especially in controversy mapping, will set the tone to some very interesting innovations, which we will discuss later on.

\section{Digital social research and online media}

Speaking in general terms, the research in the growing area of the Digital Humanities combines methodologies from the humanities with computing tools to analyse both digitized and digitally native (Rogers, 2013) material. Of course, this promising approach generates quite a few challenges for equalizing the largely quantitative approach of computational methods with the critical and qualitative traditions of humanistic fields. Digital social research, especially through the recent works of Rogers (2013), Latour (2012), Venturini (2015), Marres (2015) and others, takes one step further by going beyond the analysis of circulating content and using data derived from digital networks as a source for descriptions and analyses of society in general. Bruno (2012), for example, posits that the data generated from the interactions in digital media can be sources for approaches that differ from the critical studies of cyberculture and from the broad and relevant discussion about the strategies for sale, surveillance and control through data. She advocates an approach towards a knowledge of traces (p.3): as more and more of our lives is described as data and more of our actions are connected and tracked by information systems, the traces we leave in these systems can tell us much about the interactions that compose social live, helping us to describe and analyse it (Venturini \& Latour, 2010). Working along the same lines, Rogers (2013) posits that, instead of using digital technologies to further traditional methods of social research, or even discussing the specificities of social relations inside digital culture, social sciences should approach the data produced through digital media as evidence for the analysis of social concerns in general.

Venturini \& Latour (2010), on the other hand, ponder that social sciences have done nothing to merit such an abundance, and now face the difficult challenge of adapting and repurposing data that was not originally recorded for the interests of scientific research, let alone for specific inquiries. It becomes necessary to ground (Rogers, 2013) these digital traces so that scientific findings may really refer to social interactions and not just 
be effects of the prestructuring of data that is carried out in platforms and devices. So one needs to develop a critical understanding of the workings of the media where the data are extracted and equally of the devices produced to analyse data. This will also entail a return to media theory, semiotics, discourse analysis, cultural studies and aesthetics. We understand that the need for this critical understanding is not restricted to digital methods of social research: it is nowadays in the center of public debate. It happens necessarily through a critical approach of the media outlets and of their role in building public opinion or feeding public debate, and also through a dispute regarding the interpretation and contextualization of social events and interactions, that is, regarding the way in which society it technically mediated.

Controversy mapping is a digital method of social research developed initially at Sciences Po, from the work of Bruno Latour. The method uses digital traces left by actors as they interact with today's information and communication networks to map out controversies and develop descriptions of social reality. According to Venturini \& Latour (2010), the importance of using these digital traces and of their recent availability with the internet derives from the fact that these can help researchers track and represent the social fabric in its processes. Traditional empirical methods in the social sciences would have to work mostly with stabilized documents, institutions or social assemblages and, from there, try to picture the many disputes and transformations involved in making and maintaining them. These digital traces, on the contrary, are unfinished, fleeting, they stand for exchanges, interactions, tiny relations and, when harnessed and treated, can help visualizing debates, disputes and all the effervescence and controversy that happens until some social entity is stabilized, and also the efforts for keeping it that way. Using digital traces also helps building relational approaches while assembling representations of social reality: differently than the aggregated view of traditional statistics, they seek to focus on interactions between actors.

So the use of digital tools and online data is praised for allowing the analysis of controversies while they are hot and in the making, therefore the progressive entanglement of controversy mapping with media processes and sources, like news outlets, online forums and social media sites, where much of today's debates can be tracked. From that also comes their effort for developing maps with which the actors of the controversies may engage: they understand that representations of social life are part and instruments of the social interactions. Therefore, an important discussion among its practitioners is how to integrate the actors of controversies in the production of the maps, returning them as instruments for the controversies themselves. As we discussed elsewhere, some of the appropriations of this method (and of social network analysis in general) have been taking up more engaged roles, somehow blurring the separation between social research and activism, the academy and digital citizenship (Carvalho \& Boechat, 2014).

Venturini (2012) advances that controversy mapping is not a method for social intervention, which is a very innovative and powerful claim, but, on the other hand, we should keep in mind that the adoption of those maps by the engaged publics must include political action of citizens inside the controversy. We are using the term political in its broader sense, that runs across states, institutions and everyday life. This comes to emphasize the role of the visualizations as tools for debate, for gathering people around pressing issues. Like Virno (2008) explains, in heavily mediated societies, political action gets intertwined with the basic features of language and cognition, and disputes take place mostly in a symbolic level, precisely in the encoding and decoding processes. These set the stage for the disputes that define how to frame collective issues and the resources to debate them, like in the maps of meaning as defined by Hall (1993). When visualizations that aim at creating shared landscapes are appropriated by concerned publics, one should expect, and aim for, a coincidence between debate and political action.

\section{Repurposing the platform, revealing the debate}

The very specific perspective developed in controversy mapping will entail two main challenges that are relevant to our discussion: first, dealing with the biases present in every platform and the ways in which they organize the information that is going to be used for research. Second, the challenge of building representations that will power discussions and foster participation of concerned publics. Facing these challenges will put forward two corresponding innovations, that we describe in the following lines. 
Platform bias should be a constant concern for scholars in digital social research in general. As they adapt data that was not produced for the goals of the specific inquiry they are working on, the criteria of the platform where the data was produced or initially organized will be transferred to the context of the inquiry and must be carefully considered. The hashtags in Twitter, for instance: on the one hand, they are very useful because they allow the selection of related tweets and the mapping of them into networks for analysis. On the other hand, these maps will not show posts with other related hashtags that might be part of the discussion, neither will they account for ironic or misplaced use of them. In other words, the formation and use of such hashtags inside the exchanges between users is seldom discussed. As Marres (2005) points out, to an extreme, scholars might end up studying the platform and not the social issues at stake in the inquiry, because the platform biases affect the framing of the issues that are being studied. On another extreme, we could say that there is the danger that scholars do not succeed in identifying the disputes and power struggles present in the structuring of the data they are appropriating. So digital methods, at the same time, profit from information architectures in order to track social interactions, but must develop a deep concern for revealing the constraints of these structures and, to a certain extent, the power struggles involved in it.

We draw attention to the fact that the platform biases can cause distortions in the data and its interpretation, but are fundamentally part of the process of technical mediation: each interface or information architecture organizes a certain set of rules and offers some tools for enunciation, like an ethos that is meant to fade to the background for the sake of usability. Again, a strong example comes from social media: sites like Facebook, for example, are constantly making improvements in their interface's structure and adding new features. For a while along its first years, there were many of such updates, and at each one we had the impression that it would be hard to adapt, but soon found ourselves not remembering how the interface was structured previously. The features had quickly faded into the background, as an encoded base structure that maps the means for our exchanges and debates. And that is why developing a critical stance for working with data that is bred according to these discursive codes can be quite tricky. Because of that, in a more general aspect, this will also involve understanding the many processes of mediation and encoding and decoding that go through in the circulation of messages and their appropriation in social practices, something that will in many instances guide the process of visual data analysis itself during the exploratory stages of the inquiries.

So on the one hand we have the use of these objects (tags, hashtags, classifications, entries, hierarchies, orders etc.) of information architecture as starting points or handles to draw data from the flow of online media, and, on the other hand, we have the effort for creating critical standpoints towards them, revealing and working productively with their biases, as part of the issue being discussed. We believe this lays out an important path for the development of methods like controversy mapping, because it enables scholars to address issues that are often left on the background, even in traditional social research. We understand that this effort reverses mediations because it uses information architectures to draw data, but also, considering that an ideal of overcoming them would be not only impossible but undesirable, may reveal the biases and the power struggles that may structure them, pushing the inquiry forward. 


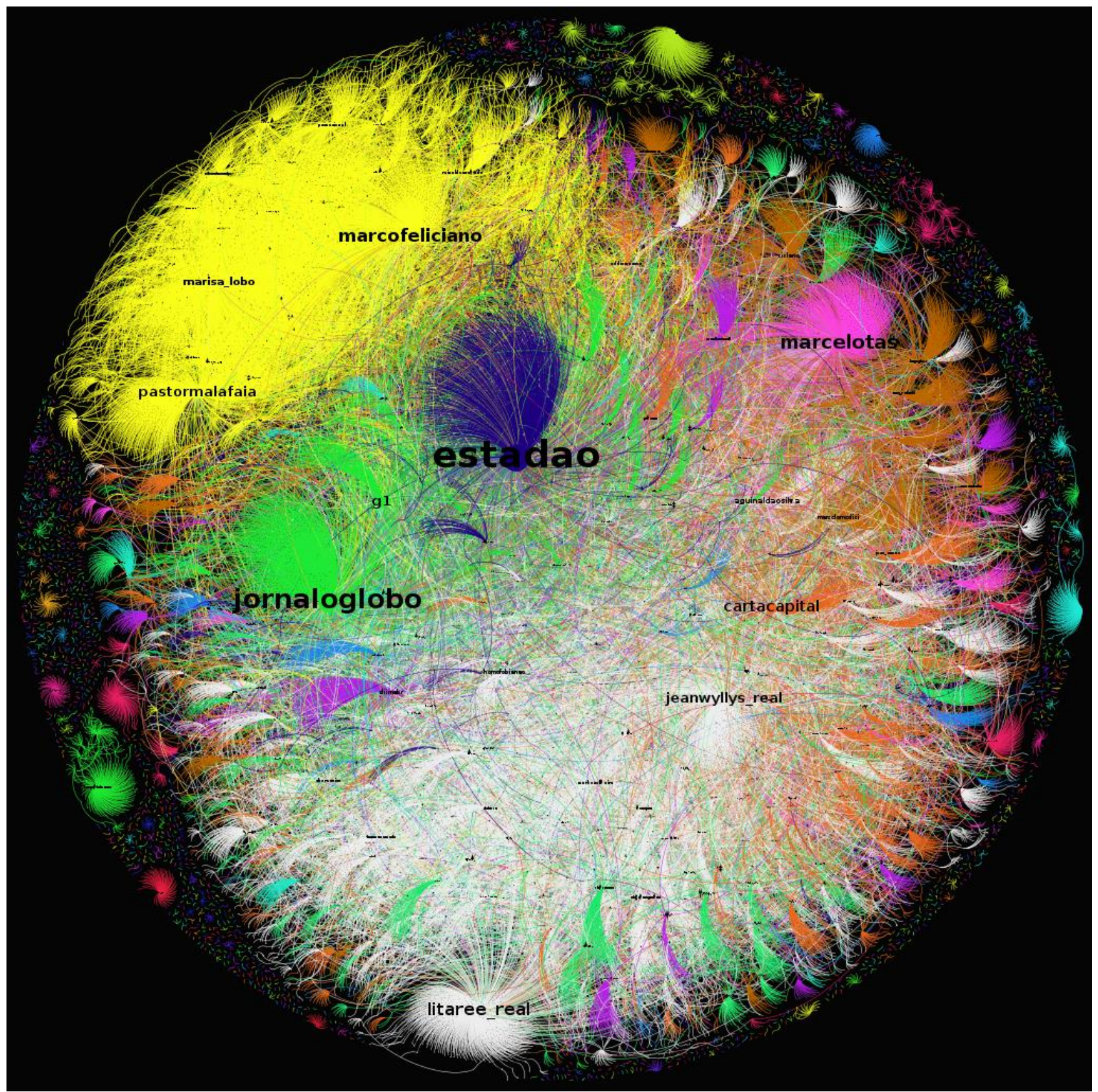

Figure 1. Network showing the sharing of Twitter posts tagged \#Feliciano, by Fabio Malini. Source: http://www.labic.net/imprensa-nas-redes-sociais-autoridade-sem-centralidade

The second challenge we would like to draw attention to is directly connected to visual data analysis, and to producing and sharing the maps of controversy. Indeed, visualization is a central issue for the practice in controversy mapping: it reveals and even orients a careful work of extracting data that is circulating in the medias and reprocessing and repurposing it in new informational forms, the controversy maps. According to Munk, visiting professor at the médialab Sciences Po and researcher at Emaps Project (apud Boechat, 2015), visualization is in the very roots of the method and, at the same time, brings a whole new sense to scientific inquiry, because it allows for the participation of a wider range of specialists and actors, and becomes a space in which the inquiries become visible and are collectively developed. Meunier, project manager of Emaps Project at médialab Sciences Po (apud Boechat, 2015), believes visualizations should come into the research process as early as possible: they should be specified and streamlined iteratively, together with the research questions. 
In fact, the aim of controversy mapping seems to be to take on a very bottom-up approach to social analysis through visualization (see, for example, Venturini et alii, 2015, p.6-10).

One last important aspect of the use of visualization is its dissemination for the engaged publics: those are people that may gather around artifacts like controversy maps because they are engaged or affected by a certain issue. Munk understands that involving actors of the controversy in the mapping process gives scholars important hints about platform biases and of how to interpret and treat the data. Venturini et alii (2015), on the other hand, point to the possibilities of participatory design methods and to improving the maps according to the ways in which they are adopted, creating iterative cycles. So the maps themselves must be seen as part of the controversy and, if they succeed in being adopted by concerned people, they can also become an axis for following its development.

As might have become evident, this work of controversy mapping is not straightforward, neither is the effort we see in it, of reversing mediations. Building network maps based on tweets and retweets that use a specific hashtag, for example, where each node is a profile and each connection is a retweet will tend to show the relevance of the most popular profiles like the ones of major news outlets and media personalities. This approach does show the penetration of large media companies and their encodings in social media, but much of the exchanges themselves gets masked behind the central sources, and also there is no hint of how these dominant encodings are being decoded and incorporated into more distributed discursive practices.

See, for example, the graph built by Malini (2013) in figure 1, showing a network of tweets with the hashtag \#Feliciano, formed by profiles in twitter (nodes) and the retweets of their tweets (vertices). That is: raw data listing posts in Twitter that were tagged with \#Feliciano for a certain timeframe was downloaded. For every post, the data showed its author and the reposts, that is, when other users forward the post to their own network of followers. Bigger nodes show users whose posts were forwarded the most, as a measure of popularity, and lines connect the users that forwarded posts. The different colors show the different communities present in the network. The hashtag \#Feliciano refers to Marco Feliciano, a Brazilian politician that aims at passing laws and making state policies that threaten the separation between church and state, as well as the safety and equal rights for minorities, especially the homossexuals. When he was nominated chair for the Human Rights Commission of the Deputies Hall in Brazil this generated much controversy and disputes between activists from religious groups and human rights groups.

By itself, this network highlights the popularity of certain profiles (in general from large media outlets and celebrities), and the proximity between profiles that forward similar posts, but it fails to display the real conversation and the exchanges between profiles, the public debate. Seen isolatedly, this graph displays the surface of the concentrations of power, in terms of organizing main information flows, displays the surface of the platform structure. It does not reach the layer of the real controversies and, to use Hall's (1993) words, the decoding moments, where media messages are translated into practices. So, even though this graph relates many elements, we start to wonder if it would not have a clearer impact if presented, for example, as a series of column graphs, showing the amount of retweets for each main profile.

For Malini, this should be addressed by taking into account the difference between two metrics that are used in network analysis: authority and centrality. In the case of Twitter, large and professional news outlets have much authority, because they are dedicated to reporting, and have privileged access to many sources, so people tend to follow their profiles and frequently forward the content they post. They are seen as references for specific kinds of news. Centrality, on the other hand, refers to the proximity a profile has to others, in the sense of having his content forwarded but also of forwarding content. This means that profiles that really engage in the conversation will be more central: they may not generate as much content, but their participation will be more determinant for building discourses and shaping debate. Malini explains that profiles with great centrality have their messages circulating longer and across more connections than profiles with only large authority, because their networks are tighter and more interconnected. Therefore, to better analyse the debates about Marco Feliciano from the dataset, one should build series of graphs, in order to deploy different aspects of the data. 
PROFILES OF SCEPTICISM, MITIGATION, ADAPTATION, AND CONFLICT IN TWITTER

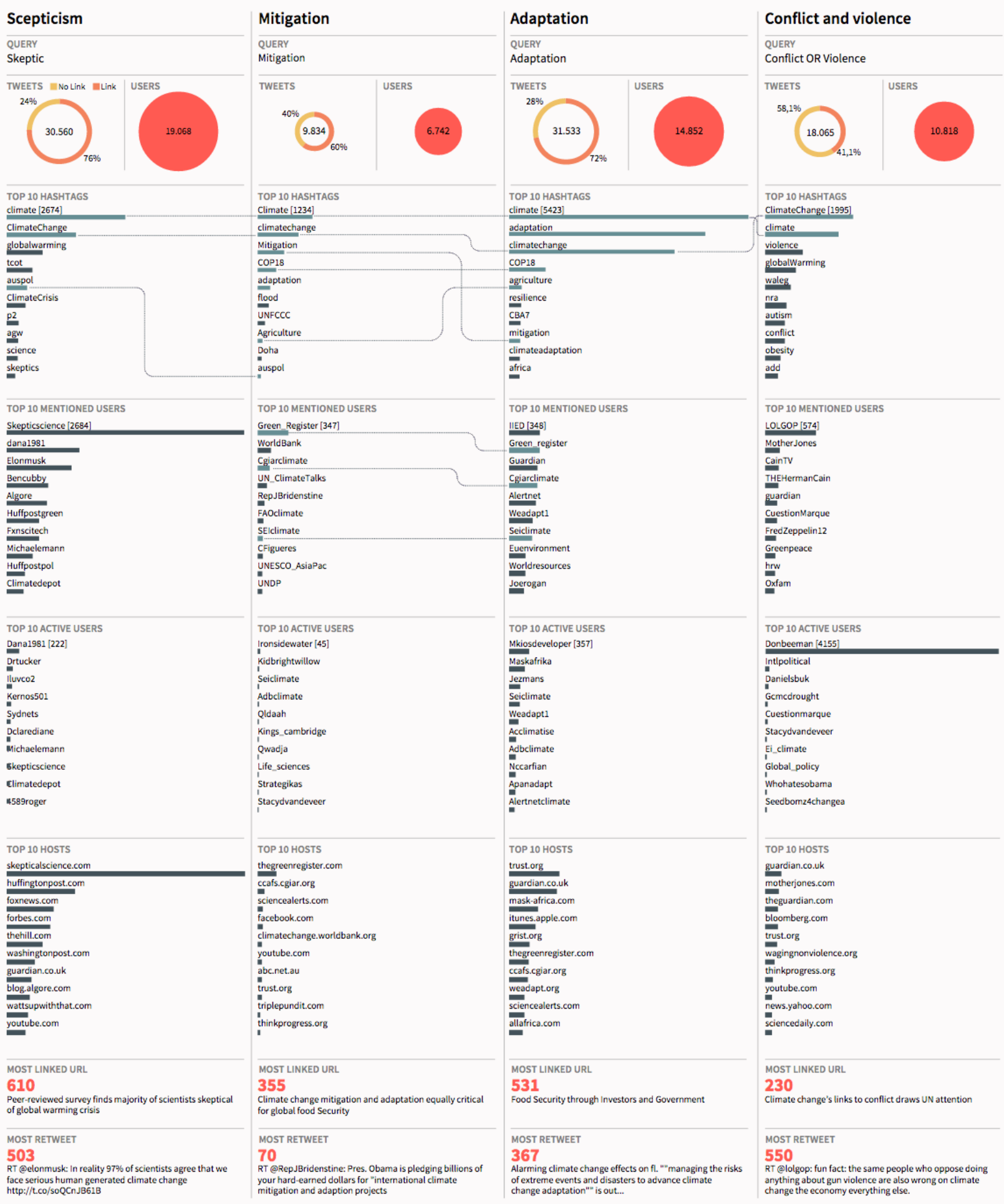

Figure 2. Profiling Adaptation And Its Place In Climate Change Debates With Twitter (I). Source: http://climaps.eu/\#!/map/profiling-adaptation-and-its-place-in-climate-change-debates-with-twitter-i 
Comparing the metrics of authority and centrality in networks will help us reach an idea of the actual conversation that is happening on Twitter by emphasizing relational aspects of the data, rather than solely quantitative ones, like popularity. This is in the core of the quali-quantitative methods that are in the base of digital social research, and allows describing social issues according to interactions between actors. But, still, we should aim at a deeper layer of analysis if we want to seek ways in which to reverse mediations: we should take profit and question the information architecture of the platform.

The Emaps project was carried out by a consortium of European research centers between 2010 and 2014, and we were able to follow some of the work of cartography that is displayed in the site with the final results of the project. They face the challenge of mapping controversies and questioning the effects of the platforms from a different perspective. One of the maps published as results of the project display a profile of Twitter accounts (figure 2) made at the DMI Summer School 2013, where the emphasis was in revealing how the subject of climate change was made into a matter of concern to be shared, that is, how it was framed and how the correspondent discursive features were built in Twitter. For that, they captured tweets from November 2012 to May 2013 that contained either hashtags or keywords in their content that were related to climate change. From this corpus, they defined four major climate change issues, queried by the terms [skeptic], [mitigation], [adaptation], [conflict OR violence], in order to generate some metrics for profiling. The graphic shows the popularity of each issue and informations like the main related hashtags and how they compare across issues. It also shows the main sources linked and the most active profiles, which gives us interesting information on the subject. The main difference here is that hashtags are not taken by face value: all these correlations aid in developing a better understanding of actually what they mean in the space they assemble. The emphasis stays on the debate and on how it is shared on Twitter.
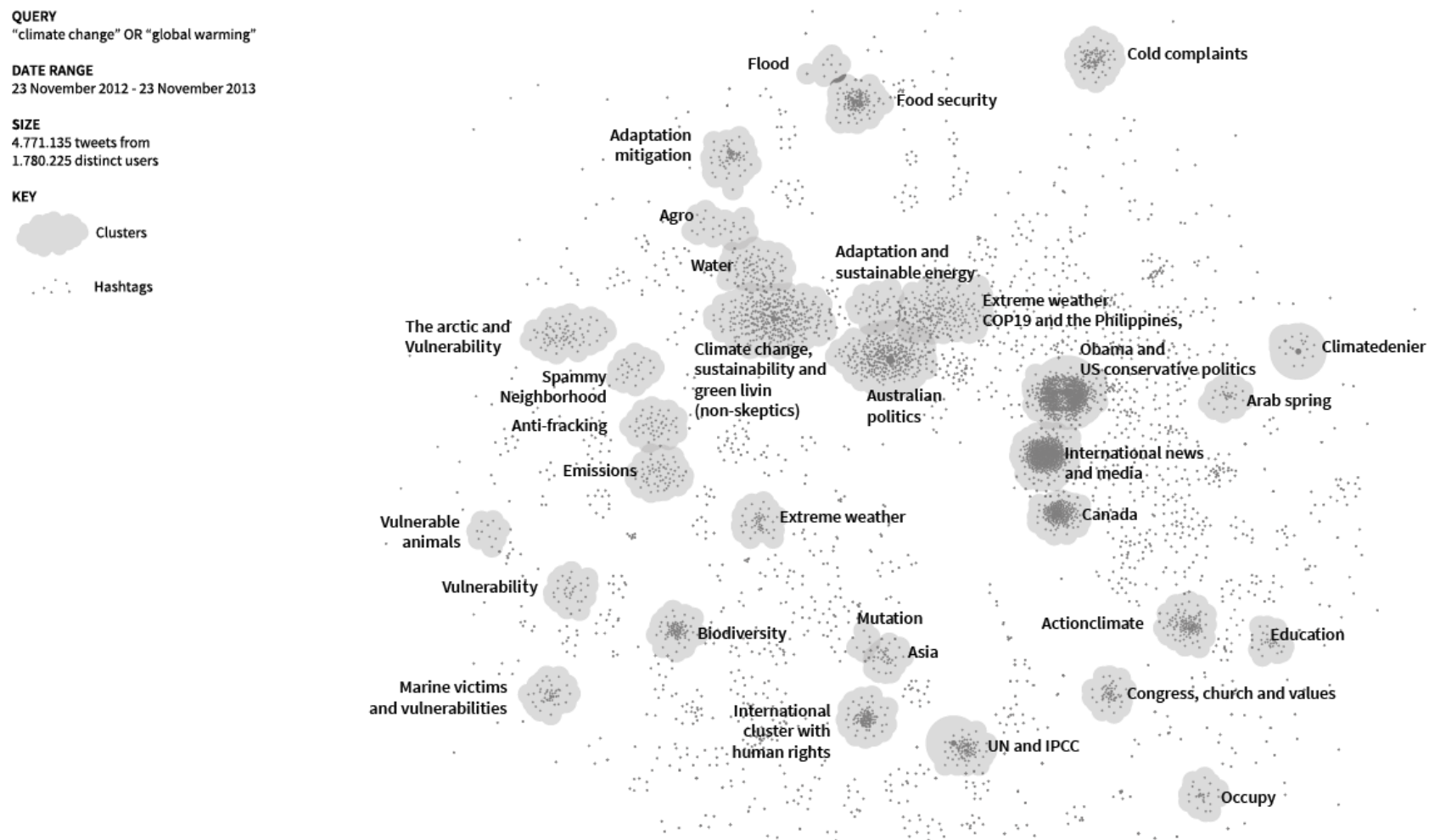

Figure 3. Profiling Adaptation And Its Place In Climate Change Debates With Twitter (I). Source: http://climaps.eu/\#!/map/profiling-adaptation-and-its-place-in-climate-change-debates-with-twitter-ii

On the results of the Emaps project, on the Climaps.eu site, this graphic is associated to a map (figure 3), that displays the main hashtags found and their proximity according to co-occurrence in tweets, inside the set of tweets that contained the hashtags or keywords "climate change" or "global warming" between November 
2012 and November 2013. This gives us yet another point of access to examining the debate on Twitter, that helps us understanding how different hashtags may be related, and thus translated in their use. The chosen theme (climate change) organizes a Twitter space, a landscape to be explored for its specific issues. Both visualizations highlight hashtags and keywords as powerful traces for organizing maps of debates, and, as their positions may shift and get reorganized, so may the positions of the many actors involved.

This comparative and relational approach also enriches the discussion because it favours a critical approach on the hashtags as platform-specific resources, in order to take a step back and evaluate also their effects and biases. This work reveals a more relational, qualitative network of arguments and gives us material to discuss the processes of attribution of signs in different maps of meaning that are involved in every decoding process. The effort of this inquiry using Twitter data reverses the mediation of the platform in order to reach new understandings. It does not replace the platform or dissolves its architecture, but proposes new and more cohesive access and interpretation.

\section{Conclusions}

Instead of working with the contents of the messages and the dominance of the distribution channels, information architectures can offer the means for yet another kind of strategy for stabilizing hegemonic discourse and encodings, in the heart of information networks. This time, this is brought on by the communicational infrastructure itself: it is in the effects of the information architectures and of the many features for managing the information flows. With online media we have both complementary aspects: more visibility and more structuring to canalize discourse and debate into the informational flow. There is a stage of dispute of meaning attributions that is displayed in how the computer interfaces are organized, how data is visualized, how the places of mediation create paths and structures and participate in broader and collective production of representations of social reality. We believe that most of the concern for the effects of the platform in the digital methods of social research comes from this entangled relation between public debate and dominant information architectures, that are fundamental for professional outlets as well as for individual users of social media or self-publishing platforms.

While traditional print and broadcast media had almost exclusivity on publishing channels, it might have been adequate, even though not precise, to describe the production and circulation of messages in society in two levels: on the one hand, the major channels and codes, the hegemonic content producers. On the other hand, the decoding level as an individual activity, either seen as a psychological behaviour, or fit into a frame of statistical behaviour that could be extrapolated into conclusions about collective message reception. Substantially, the sphere of public debate as a social phenomenon, in the level of the interactions and of the collective exchange that produces meaning, was seen as an uncharted and messy terrain where interactions and encodings were impossible to track. It is like debate could only be approached in relation to major flows of information. These approaches, even though they do bring much insight to the table, miss the point that communication has always been technically mediated, in every level, and that mediations are multidirectional. With the spread of online platforms it becomes unavoidable to carefully consider other distributed mediations as part of the media landscape, but there is no actual modification of communication flows, just intensification of exchanges and an increase in their records.

The work conducted in digital social research in general, and in initiatives that apply their methods to activism and digital citizenship, is creating new mediations, new interfaces in the form of maps, that repurpose information flows. Once there is a general recognition that technical mediation produces traces that can be used for describing society in general, these methods are discovering the strength of extracting data from information to reassess information: this translates many encodings, many structures, many discursive spaces into an assembled landscape. We understand that this reprocessing and repurposing of information reverses mediations, not in the sense of inverting flows, but in the sense of problematizing and surpassing information structures. After all architecture, there might be a recovery of the plasticity for information through data extraction and visual analysis. 
We stress terms like "reversing" or "repurposing" in order to avoid thinking of visualizations, in the context of reverse mediations, as yet another layer that piles up our already overlayered experiences. We have found that, when one seeks to map debates, there is the risk that the representations start to be seen mostly as meta-debates, the debate about the debate, accumulating indefinitely layers of representation of debates about debates. Indeed, even without mapping, debates will of course take place with the use of many and contradictory representations of a certain issue, and there would be neither an issue nor an engaged public if all the representations and codes coincided. So we believe this movement of reversing, or bringing the informational structures inside out, is crucial for equipping citizenship in heavily mediated societies, not exactly because of what is represented, but because of the many points of access it offers to a complex communicational landscape.

\section{References}

Boechat, Marina. Making visible things: on the uses of visualization for building a shared world; the cases of data journalism and controversy mapping. 2015. $261 \mathrm{f}$. Tese (Doutorado em Comunicação e Cultura) Escola de Comunicação da Universidade Federal do Rio de Janeiro, Rio de Janeiro. 2015.

Bruno, Fernanda: Rastros Digitais: o que eles se tornam quando vistos sob a perspectiva dateoria ator-rede? In: ENCONTRO DA COMPÓS, 21., 2012, Juiz de Fora. Anais. Juiz de Fora:Compós, 2012. Avalable: http://www.compos.org.br/data/biblioteca_1798.doc

Guedes, Roger de M.; Moura, Maria Aparecida; Dias, Eduardo J. W: Indexação social e pensamento dialógico: reflexões teóricas. Inf. Inf., Londrina, v. 16, n. 3, p. 40-59, jan. Jun. 2011.

Hall, Stuart: Encoding, decoding. In DURING, Simon (ed.). The cultural studies reader 4. Routledge: London, 1993, p.80-103.

Latour, Bruno: Reassembling the social: an introduction to actor-network theory. Oxford University Press: Oxford, 2005.

Jensen, P., Venturini, T., Grauwin, S., \& Boullier, D. "The Whole is Always Smaller Than Its Parts" A Digital Test of Gabriel Tarde's Monads.British Journal of Sociology,63(4), 591-615, 2012. Available: http://www.tommasoventurini.it/wp/wp-content/uploads/2013/05/TheWhole.pdf

Malini, Fabio. Imprensa nas redes sociais: autoridade sem centralidade. Site Labic - Laboratório de Estudos sobre Imagem e Cibercultura, 2013. Available: http://www.labic.net/imprensa-nas-redes-sociais-autoridade-sem-centralidade/

Marres, Noortje. Why Map Issues? Controversy analysis as a digital method. (draft) Available at: https://Www.academia.edu/9588591/Why_Map_Issues_On_Controversy_Analysis_as_a_Digital_Method.

. Issues spark a public into being. A key but often forgotten point of the Lippmann-Dewey debate. Em Latour, Bruno; Weibel, Peter (eds.). Making Things Public, MIT Press, Cambridge MA, 2005

The New York Times: Innovation Report. 2014. Available: http://www.presscouncil.org.au/uploads/52321/ufiles/The_New_York_Times_Innovation_Report__March_2014.pdf

Pereira, Débora Carvalho; Boechat, Marina Pantoja. Apenas siga as mediações: Desafios da Cartografia de Controvérsias entre a Teoria Ator-Rede e as mídias digitais. Contemporanea (UFBA. Online), v. 12, p. 556-575, 2014.

Venturini, T. \& Latour, B. "The Social Fabric: Digital Traces and Quali-quantitative Methods". Proceedings of Future En Seine, 2010. Available: http://www.medialab.sciences-po.fr/publications/Venturini_LatourThe_Social_Fabric.pdf. Access: 05/032015.

Venturini, T., Ricci, D., Mauri, M., Kimbell, L., \& Meunier, A. Designing Controversies and their Publics. Design Issues, 31(3), 2015. Available: http://www.tommasoventurini.it/wp/wp-content/uploads/2014/08/Venturini-etAl_Designing-Controversies-Publics.pdf

Virno, Paolo. Virtuosismo e revolução: a idéia de "mundo" entre a experiência sensível e a esfera pública. Rio de Janeiro: Civilização Brasileira, 2008. 